\title{
Patient Self-Management of Asthma Using Mobile Health Applications: A Systematic Review of the Functionalities and Effects
}

\author{
Mehrdad Farzandipour ${ }^{1,2}$ \\ Shima Anvari ${ }^{2,3}$ \\ ${ }^{1}$ Health Information Management Research Center, Kashan \\ University of Medical Sciences, Kashan, Iran \\ 2 Department of Health Information Management and Technology, \\ School of Allied Health Professions, Kashan University of Medical \\ Sciences, Kashan, Iran \\ ${ }^{3}$ Student Research Committee, Kashan University of Medical \\ Sciences, Kashan, Iran \\ ${ }^{4}$ Department of Pediatrics, Faculty of Medicine, Kashan University of \\ Medical Sciences, Kashan, Iran
}

Appl Clin Inform 2017;8:1068-1081.

\author{
Address for correspondence Ehsan Nabovati, MSc, PhD, Qotbe \\ Ravandi Boulevard, Pardis Daneshgah, Health Information \\ Management Research Center, Kashan University of Medical Sciences, \\ Kashan, Iran (e-mail: Nabovati@kaums.ac.ir).
}

\section{Abstract}

Keywords

- asthma

- chronic diseases

- patient self-care

- e-health

- smartphone
Objective The aim of this systematic review was to summarize the evidence regarding the effects of mobile health applications (mHealth apps) for self-management outcomes in patients with asthma and to assess the functionalities of effective interventions.

Methods We systematically searched Medline, Scopus, and the Cochrane Central Register of Controlled Trials. We included English-language studies that evaluated the effects of smartphone or tablet computer apps on self-management outcomes in asthmatic patients. The characteristics of these studies, effects of interventions, and features of mHealth apps were extracted.

Results A total of 10 studies met all the inclusion criteria. Outcomes that were assessed in the included studies were categorized into three groups (clinical, patientreported, and economic). mHealth apps improved asthma control (five studies) and lung function (two studies) from the clinical outcomes. From the patient-reported outcomes, quality of life (three studies) was statistically significantly improved, while there was no significant impact on self-efficacy scores (two studies). Effects on economic outcomes were equivocal, so that the number of visits (in two studies) and admission and hospitalization-relevant outcomes (in one study) statistically significantly improved; and in four other studies, these outcomes did not improve significantly. mHealth apps features were categorized into seven categories (inform, instruct, record, display, guide, remind/alert, and communicate). Eight of the 10 mHealth apps included more than one functionality. Nearly all interventions had the functionality of recording user-entered data and half of them had the functionality of providing educational information and reminders to patients.

Conclusion Multifunctional mHealth apps have good potential in the control of asthma and in improving the quality of life in such patients compared with traditional interventions. Further studies are needed to identify the effectiveness of these interventions on outcomes related to medication adherence and costs. received

July 8,2017

accepted after revision

September 16, 2017
Copyright @ 2017 Schattauer
DOI https://doi.org/ 10.4338/ACI-2017-07-R0116.

ISSN 1869-0327. 


\section{Background and Significance}

Asthma is a common, chronic, noncommunicable disorder of the respiratory tract, affecting more than 334 million people of all ages in all parts of the world ${ }^{1}$ and it is predicted that the number of patients with asthma will increase by 100 million more by $2025 .^{2}$ Asthma affects negatively the different domains of quality of life of patients due to long-term treatment and multiple attacks. Asthma is a growing cause of morbidity and mortality ${ }^{3}$ and imposes a significant burden on patients, families, and healthcare systems such that it is known as the third-ranking cause of hospitalization among children. ${ }^{4}$ It was estimated that a mean cost per year for each asthmatic patient in Europe and United States is \$USD 1,900 and 3,100 , respectively. ${ }^{5-7}$

An effective way to reduce costs and the harm caused by asthma, like most chronic diseases, is the management of the disease by the patients (self-management). ${ }^{8}$ Asthma-related outcomes such as unscheduled care (e.g., admissions, hospitalizations, emergency department attendances, and doctor consultations), markers of asthma control (e.g., days of restricted activity, night disturbance, and school absence), exacerbations, and quality of life can be improved with optimal self-management. ${ }^{9-11}$ According to the guidelines on asthma management, ${ }^{12-14}$ patient education in the treatment of asthma is essential and the main emphasis is to increase patients' knowledge and to promote patients' adherence to treatment regimens. ${ }^{15,16}$ Some problems such as nonadherence to medications and the lack of information about self-management have led to unwillingness of asthmatic patients to disease management activities. ${ }^{17}$

Due to the poor implementation of asthma self-management programs and their underutilization by patients, there is a need for innovative patient self-management methods. ${ }^{18-20}$ Information technology-based (IT-based) interventions such as mobile health (mHealth) applications (apps) have potential to enhance self-management outcomes through the provision of supports (e.g., information, education, and reminders) to patients. ${ }^{21}$ Estimates show that more than a billion people around the world will use mHealth apps on their smartphones by $2018 .^{22}$ Moreover, mHealth apps are regarded as a multifunctional media to communicate information, share experiences, and collect patients' data, and they are highly customizable, low cost, and easily available. Therefore, this type of intervention has the potential to improve self-management for patients with chronic diseases. ${ }^{23-27}$

So far, several studies have been conducted to evaluate the effects of mHealth apps on self-management outcomes in asthmatic patients, but all these studies reported different results. $^{28-32}$ For example, a study showed that a mobile phone-based interactive self-care intervention improves pulmonary function, quality of life, asthma symptoms, and medications used and reduces rate of acute exacerbations. ${ }^{32}$ However, another study showed that the use of a smart phone application does not have a significant impact on asthma control, self-efficacy, quality of life, number of acute attacks, and admissions. ${ }^{29}$ Therefore, to determine the over- all impact of these types of interventions, it seems necessary that the effects reported by individual studies aggregate in a systematic review.

According to our knowledge, several systematic reviews have been conducted on the use of IT-based interventions to promote self-management in patients with asthma. ${ }^{23,33,34}$ In 2013 , a systematic review was conducted to assess the effects of smartphone-based apps on self-management outcomes in patients with asthma. Only two randomized controlled trial (RCT) studies were included in that study; and finally, due to the small number of studies conducted in this field, it did not achieve clear and definitive results. ${ }^{23}$ Then in 2014, a metareview was conducted with the aim of evaluating the effectiveness of digital or online interventions on the outcomes of self-management in patients with asthma. This study demonstrated the positive impact of such interventions on some self-management outcomes, including quality of life and adherence to medications. ${ }^{33}$ A systematic review was also recently conducted in 2016 on 12 studies with a wide range of IT-based interventions with a focus on the features of these interventions (e.g., education, monitoring/electronic diary, action plans, medication reminders/prompts, facilitating professional support, raising patient awareness of asthma control, and decision support for professionals). That review showed that the most successful interventions included multiple features, but effects on health-related outcomes in asthma patients were inconsistent. ${ }^{34}$

The aforementioned review studies show that the number of studies performed regarding the effects of mHealth apps on the outcomes of patients with asthma in recent years has increased. According to our knowledge, since 2013 no new systematic review has been focused on the effects of mHealth apps on self-management outcomes in asthma patients. Understanding the functionalities of asthma apps helps researchers to develop a tailored content for their interventions. Therefore, to determine these functionalities and to support the widespread effective use in clinical practice, in addition to identifying information needs for asthmatic patients, ${ }^{35}$ potential effects and the features of mHealth apps should be regularly reviewed.

\section{Objective}

The aim of this systematic review was to summarize the evidence regarding the effects of mHealth apps for a variety of self-management outcomes in patients with asthma and assess the functionalities of this type of interventions.

\section{Methods}

\section{Data Sources and Search Strategies}

The electronic databases searched were Medline (via PubMed), Scopus, and the Cochrane Central Register of Controlled Trials. A combination of MeSH terms and keywords related to asthma and mHealth (e.g., mobile phone, smartphone, apps, and ehealth) were used in the search strategy. The details of search strategies are described in -Appendix. The search language was English, and the 
search period was from January 2000 to July 2016 (because technologies existing prior to that time are unlikely to be representative of contemporary technologies, especially mobile health applications). ${ }^{36}$ The literature search was updated on August 2, 2016. The reference list of included studies and relevant reviews were also examined to identify additional studies.

\section{Inclusion and Exclusion Criteria}

Studies were included if they met the following criteria:

1. Participants included people with asthma at any age, their caregivers, physicians, or other healthcare providers.

2. The studies concerned the feasibility assessment, pilot testing, or evaluation of an mHealth app intervention using a smart phone or a tablet computer.

3. The studies published in English.

4. Studies used at least one approach to the promotion of self-management skills (self-management refers to the behaviors that asthmatic patients and their family members perform to reduce the effects of this disease ${ }^{37}$ ).

Studies were excluded if they:

1. Were conducted on patients with other chronic respiratory and allergic diseases.

2. Used mobile devices only to send text messages, access Web sites, or make phone calls.

3. Were reviews, conference proceedings, letters to the editor, protocols, or theses.

4. Focused only on the assessment of participants' attitude toward the mHealth apps (without intervention evaluation results).

5. Only designed and developed mHealth apps.

\section{Screening and Data Extraction}

Titles, abstracts, and full-texts were screened by two researchers independently (M.F. and R.Sh.). Full-text articles were retrieved from the searched databases and other available databases. Data were extracted from included studies using a structured form. Disagreements were resolved by discussion with a third researcher (E.N.), if necessary. For each included study, intervention characteristics, targeted outcomes, and effects of the intervention were extracted. The studies in this review were classified into four categories by the framework developed by the University of California San Francisco-Stanford Evidence-Based Practice Center: RCTs (level 1), non-RCTs (NRCTs, level 2), observational studies with controls (OWCs, level 3), and observational studies without controls (level 4). ${ }^{38,39}$

\section{Data Synthesis and Analysis}

Due to the heterogeneity of studies in terms of methodology, statistical analyses, and outcomes, meta-analysis was not appropriate. To conduct narrative synthesis, the included studies were categorized based on different characteristics including intervention features, outcome categories, and effects of interventions on outcomes. The intervention features were classified into seven groups (inform, instruct, record, display, guide, remind/alert, and communicate) according to technology functionality framework (-Appendix). ${ }^{40}$ This framework was deductively derived using several external frameworks and has been used in another study (2016). ${ }^{41}$

Outcomes that were assessed in the included studies were categorized into three groups (clinical, patient-reported, and economic outcomes) based on the American Medical Association (AMA) reports for Performance Improvement ( - Appendix). ${ }^{42}$ Similar to the systematic review by Nabovati et $\mathrm{al}^{43}$ the effect of interventions was classified as being statistically significantly positive, positive without statistical argument, not effective (not statistically significant), negative without statistical argument, or statistically significantly negative. This systematic review follows the Preferred Reporting Items for Systematic Reviews and Meta-Analyses (PRISMA) statement. ${ }^{44}$

\section{Quality Assessment of Studies}

The quality of the included studies was assessed using the Effective Public Health Practice Project (EPHPP) quality assessment tool. ${ }^{45-47}$ The EPHPP is an appropriate instrument for the evaluation of the different study designs such as RCTs, NRCTs, and OWCs. ${ }^{48}$ It contains six criteria to rate the studies: selection bias, study design, confounders, blinding, data collection methods, and withdrawals and dropouts. Each criterion was rated as strong, moderate, or weak, and then the overall quality score (global ratings) was calculated for each study. Studies with no weak ratings were given a global rating of "strong," studies with one weak rating were given a global rating of "moderate," and studies with two or more weak ratings were given a global rating of "weak." As with the data extraction stage, each study was scored independently by two reviewers (M.F. and R.Sh.), and any disagreements were resolved through discussion with a third researcher (E.N.).

\section{Results}

\section{Literature Search Results}

The search results and study selection process were summarized in the PRISMA flow diagram ( - Fig. 1). In total, 3,370 studies were found. After removal of duplicates and screening of titles and abstracts, 27 articles were eligible for fulltext review. Finally, a total of 10 studies met all inclusion criteria.

\section{Characteristics of the Included Studies}

Key characteristics of the included studies are summarized in - Table 1. A total of 50\%(5/10) of the studies were conducted in the United States, and one study in each of the following countries-United Kingdom, Australia, Taiwan, Turkey, and Canada. All the studies began to be published from 2011 onward. The duration of the interventions varied from 7 days to 6 months (median: 3.5 months, Q1: 1.46, Q3: 6).

Of the 10 included studies, 4 studies were RCTs, 3 were NRCTs, and the remaining 3 studies were observational designs without controls. The sample sizes of the studies ranged from 20 to 288 participants (median: 42.5, Q1: 20, Q3: 124). 


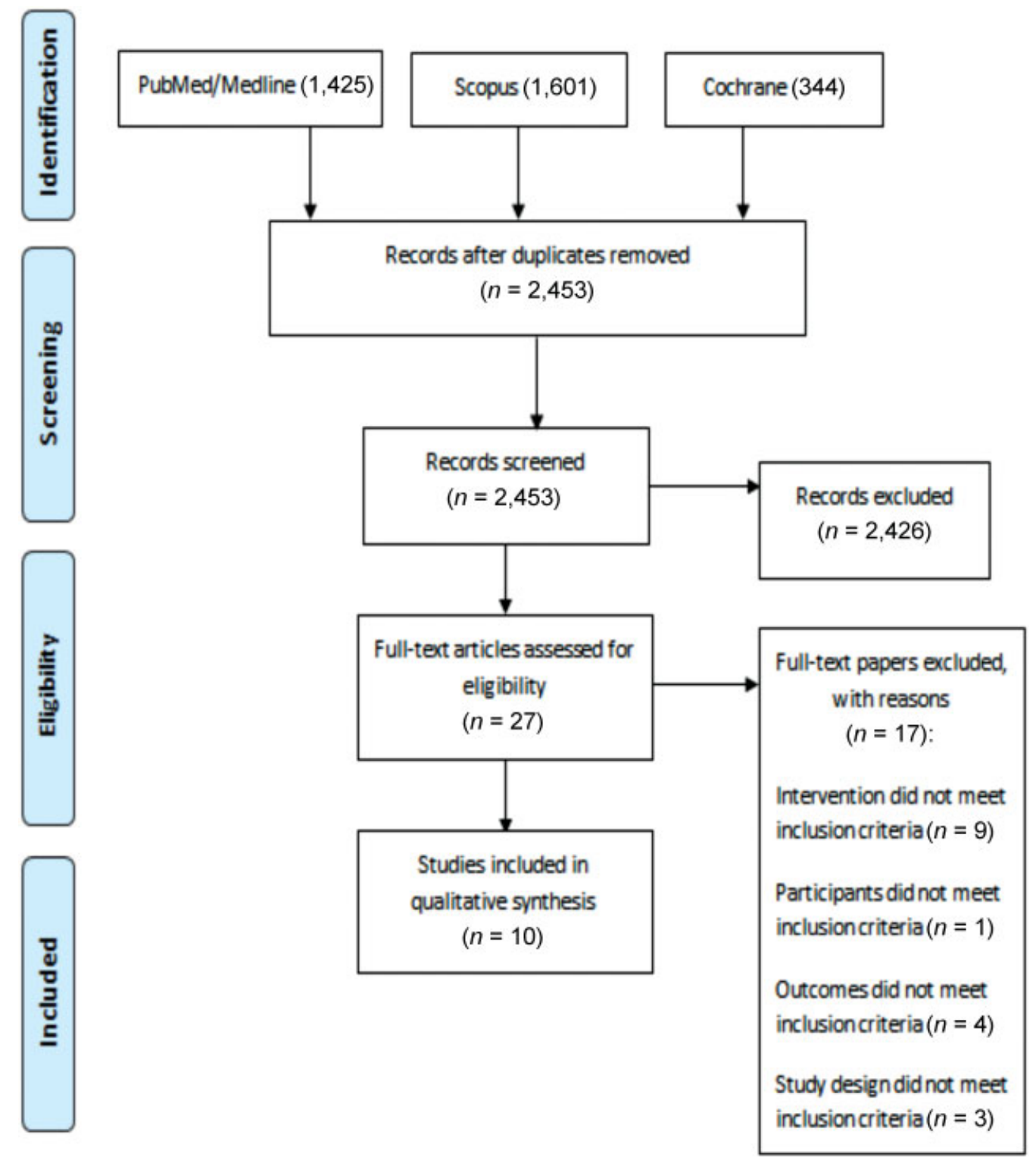

Fig. 1 Flow diagram of the literature search and study selection.

In total, seven studies involved adults and adolescents (age range: 12-82 years), one study involved teenagers (age range: 5-18 years), one study involved pregnant women (older than 18 years), and the one remaining study did not report participants' ages. In none of the included studies, participants were not children, physicians, or other healthcare providers. In seven studies, participants were patients with persistent asthma, two studies were patients with uncontrolled asthma, and in one study the type of asthma was not specified.

\section{Quality Assessment of the Included Studies}

The quality of the included studies is presented in - Table 2. The total sum shows that 50 and $70 \%$ of the studies scored moderate concerning selection bias and blinding, and 40,60, 70 , and $40 \%$ scored strong regarding study design, confounders, data collection, and dropouts, respectively. Concerning the global quality score, $40 \%$ of the studies were of strong quality, $30 \%$ moderate, and 30\% weak.

\section{Interventions Description}

According to the inclusion criteria, type of interventions in all studies was mHealth apps. In total, three studies $(3 / 10$, $30 \%)$ used both Android and iOS platforms, two studies (2/10, $20 \%)$ used iOS platform, one study $(1 / 10,10 \%)$ used Android platform, only one study used an application on the BlackBerry platform $(1 / 10,10 \%)$, and in other studies platform type did not specify. The functionalities of mHealth apps for patients were categorized into seven groups: inform, instruct, record, display, guide, remind/alert, and communicate. Details of evaluating the apps' functionalities by the technology functionality framework are presented in Appendix 1. Most studies (8/10, 80\%) employed more than one functionality. Nearly all interventions had the 


\begin{tabular}{|c|c|c|c|c|}
\hline & 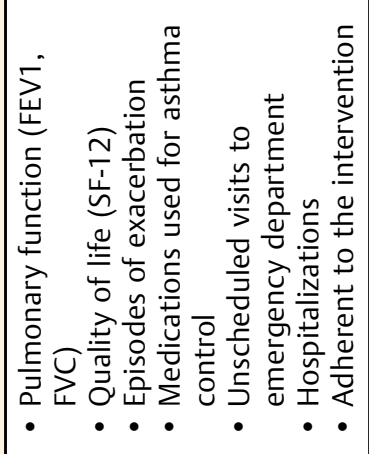 & 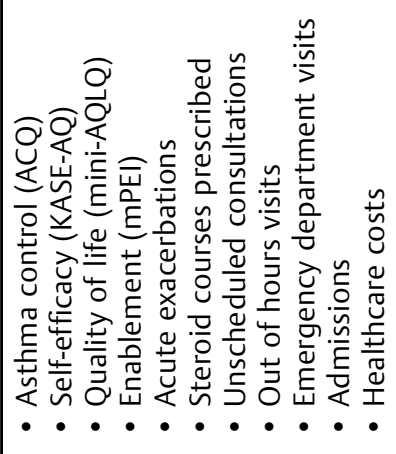 & 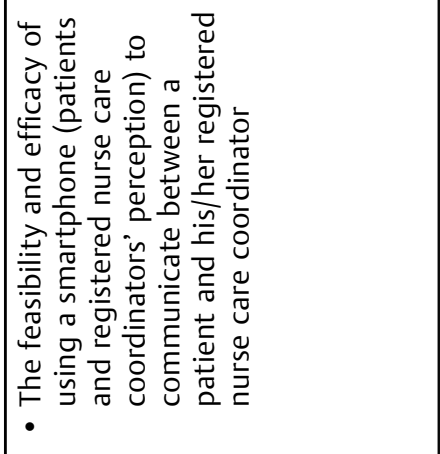 & 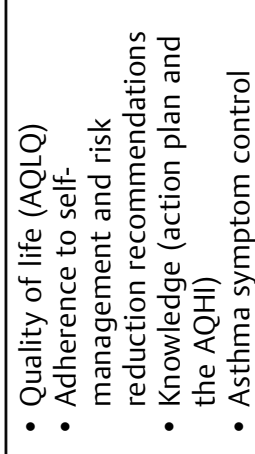 \\
\hline & 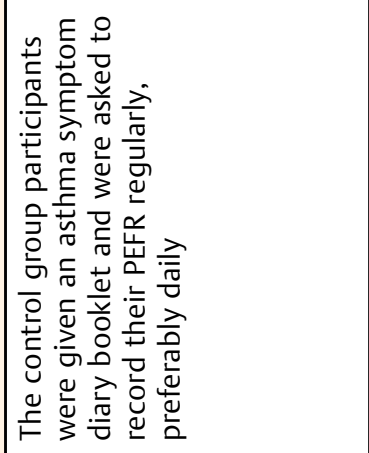 & 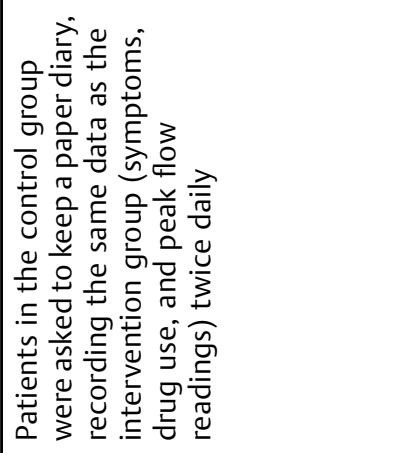 & 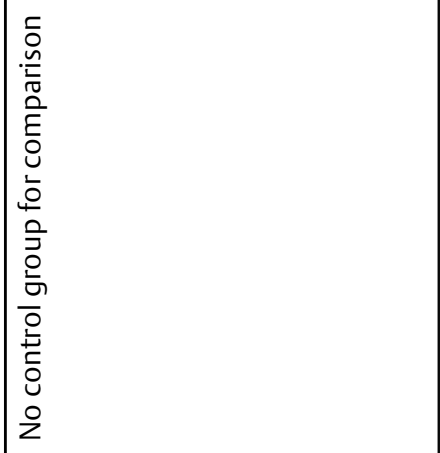 & 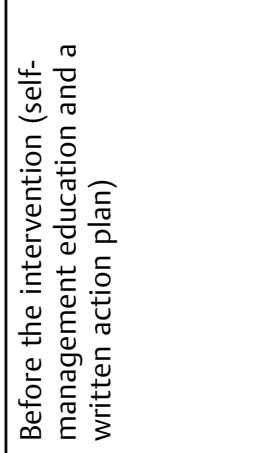 \\
\hline 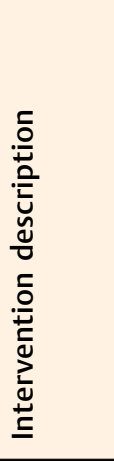 & 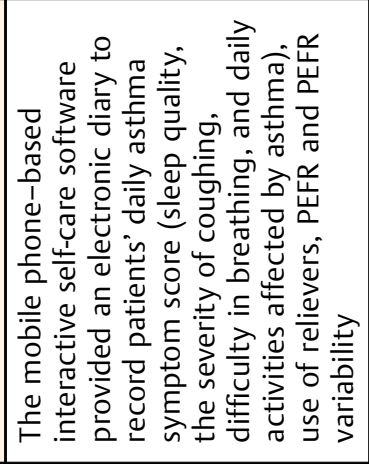 & 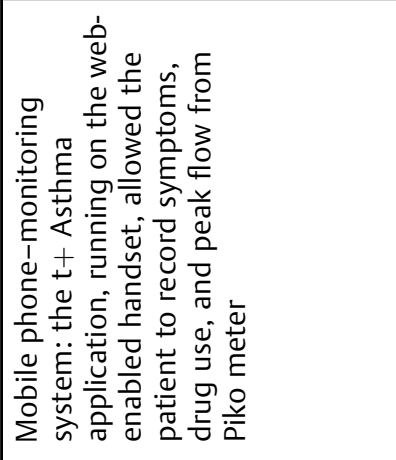 & 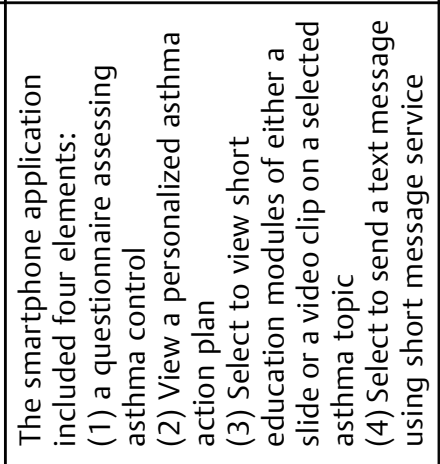 & 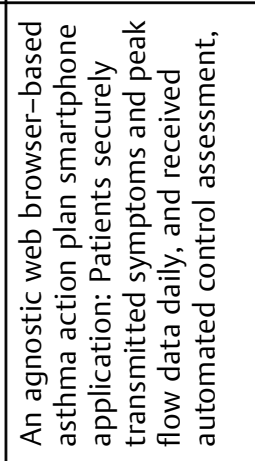 \\
\hline & 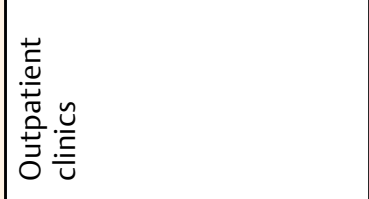 & 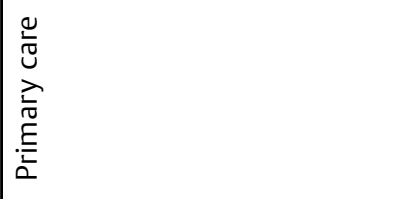 & 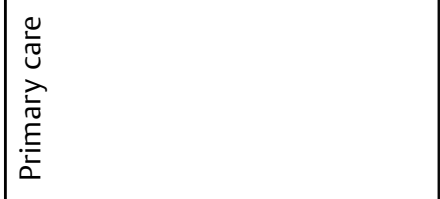 & 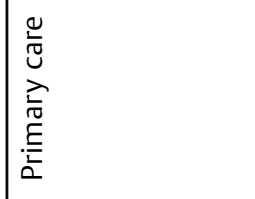 \\
\hline $\begin{array}{l}\frac{0}{0} \\
\text { E⿱ } \\
\text { ñ }\end{array}$ & 党 & 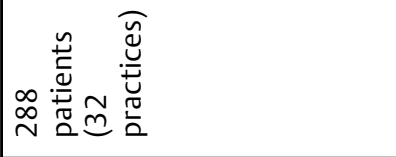 & 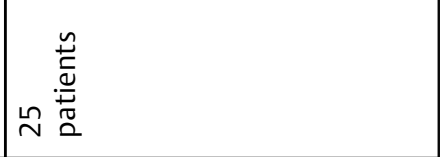 & 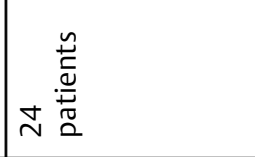 \\
\hline & 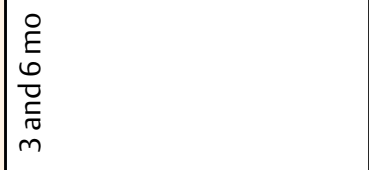 & $\begin{array}{l}\stackrel{\circ}{E} \\
\hat{E}\end{array}$ & $\begin{array}{l}O \\
\stackrel{E}{E} \\
0 \\
O \\
\stackrel{9}{m}\end{array}$ & $\frac{\varnothing}{\infty}$ \\
\hline 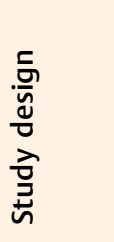 & $\underset{\propto}{\longleftarrow}$ & 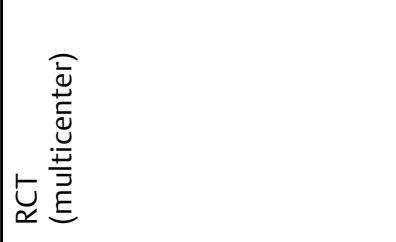 & 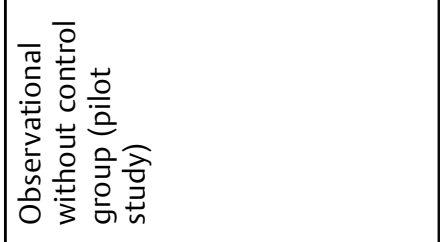 & 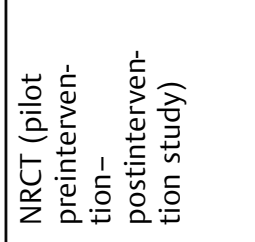 \\
\hline 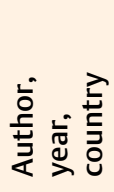 & 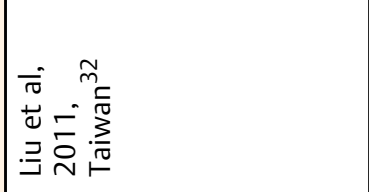 & 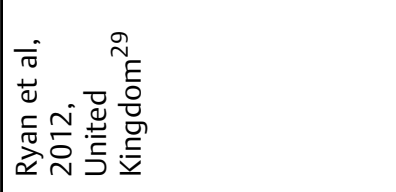 & 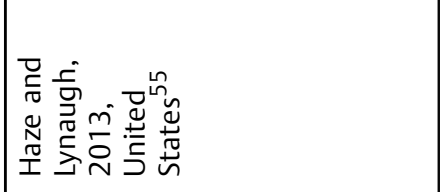 & 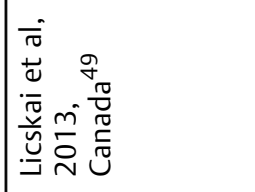 \\
\hline
\end{tabular}




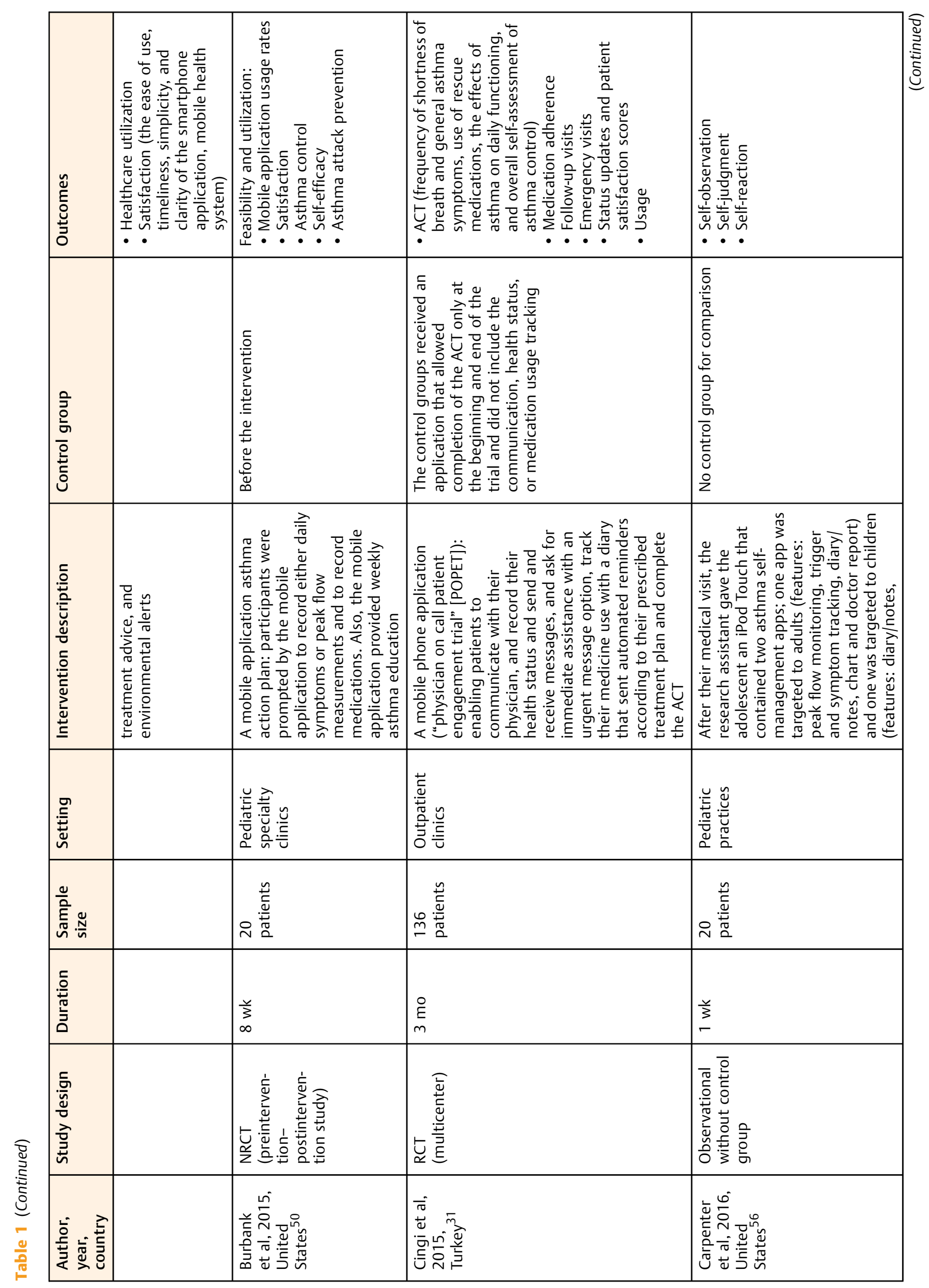




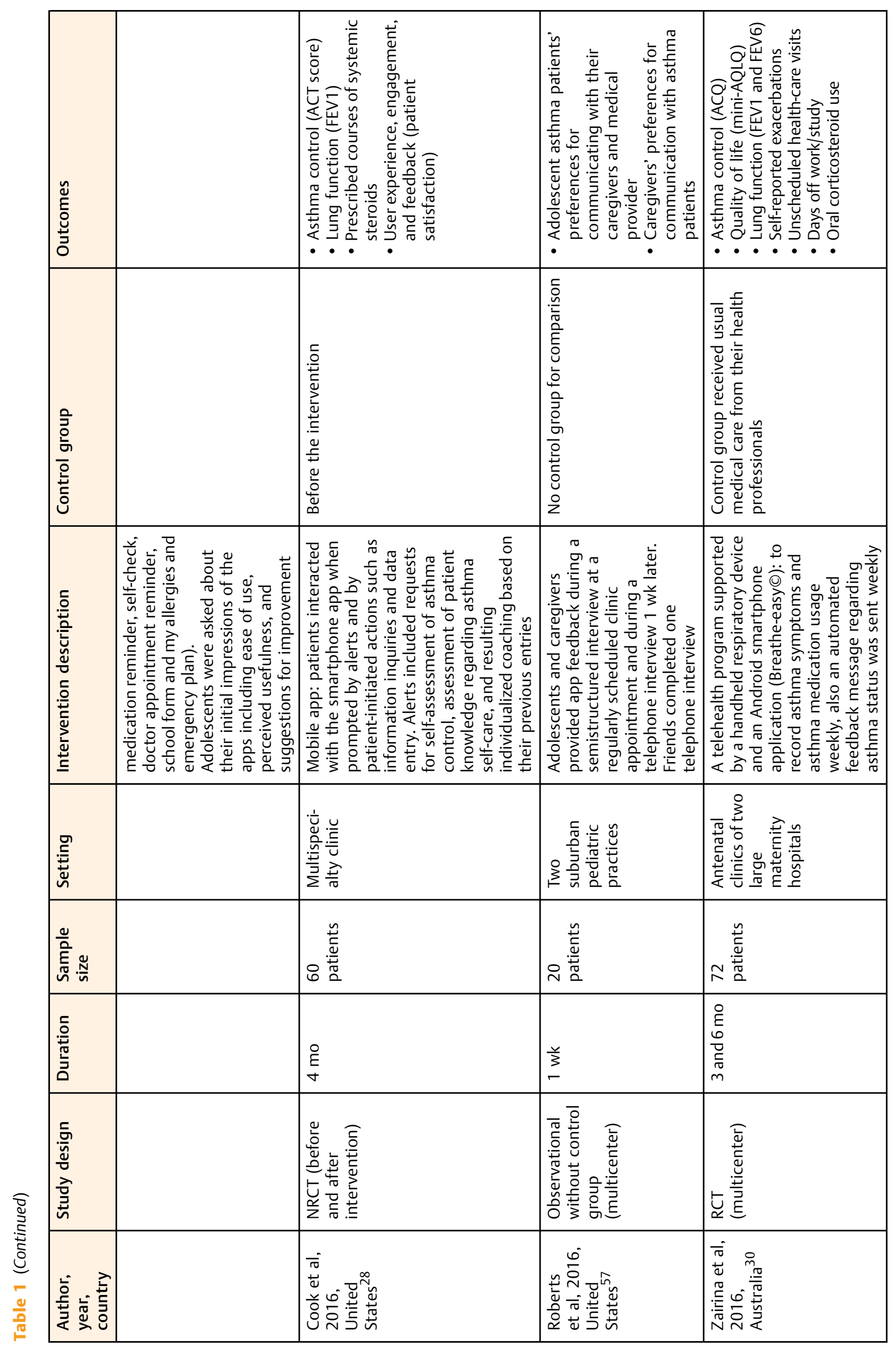

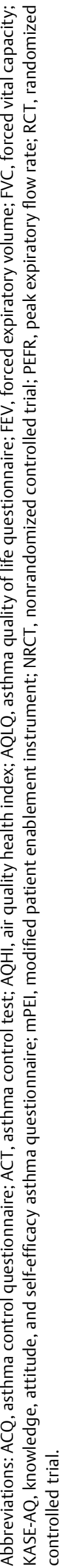


Table 2 Quality of the included studies

\begin{tabular}{|c|c|c|c|c|c|c|c|}
\hline Study & Selection bias & Study design & Confounders & Blinding & Data collection & Drop-outs & Global rating \\
\hline 32 & 3 & 3 & 3 & 2 & 1 & 2 & 2 \\
\hline 29 & 3 & 3 & 3 & 2 & 3 & 3 & 3 \\
\hline 55 & 2 & 1 & 1 & 2 & 1 & 2 & 1 \\
\hline 49 & 2 & 2 & 1 & 1 & 3 & 3 & 1 \\
\hline 50 & 2 & 2 & 2 & 1 & 3 & 3 & 2 \\
\hline 31 & 3 & 3 & 3 & 3 & 3 & 2 & 3 \\
\hline 56 & 2 & 1 & 3 & 2 & 3 & 3 & 2 \\
\hline 28 & 2 & 2 & 2 & 2 & 3 & 3 & 3 \\
\hline 57 & 1 & 1 & 3 & 2 & 1 & 3 & 1 \\
\hline 30 & 3 & 3 & 3 & 2 & 3 & 3 & 3 \\
\hline \multicolumn{8}{|l|}{ Sum (n, \%) } \\
\hline Weak & $1,10 \%$ & $3,30 \%$ & $2,20 \%$ & $2,20 \%$ & $3,30 \%$ & $0,0 \%$ & $3,30 \%$ \\
\hline Moderate & $5,50 \%$ & $3,30 \%$ & $2,20 \%$ & $7,70 \%$ & $0,0 \%$ & $3,30 \%$ & $3,30 \%$ \\
\hline Strong & $4,40 \%$ & $4,40 \%$ & $6,60 \%$ & $1,10 \%$ & $7,70 \%$ & $7,70 \%$ & $4,40 \%$ \\
\hline
\end{tabular}

Note: 3 = strong; 2 = moderate; 1 = weak.

functionality of recording user-entered data (9/10, 90\%), half of them had the functionality of providing educational information and reminders to patients, $40 \%$ of them graphically displayed user-entered data and used apps to communicate between healthcare providers and patients, and $30 \%$ of them also provided instructions and guidance based on userentered information.

\section{Effects of Interventions on Outcomes}

The categories of asthma outcomes and effects of interventions on them are shown in -Table 3. Among clinical outcomes, asthma control and lung function improved significantly in most studies which examined them. However, it should be noted that in two high-quality RCTs, ${ }^{29,30}$ these two outcomes did not change, whereas the positive results on these outcomes were from a mixture of RCTs and NRCTs of more variable quality.

In terms of patient-reported outcomes, the quality of life was significantly improved in the majority of studies that were assessed. This outcome was improved in multiple studies including a high-quality $\mathrm{RCT},{ }^{30}$ while no improvement was found in another high-quality RCT. ${ }^{29}$

There is limited evidence concerning the effects of interventions on economic outcomes. While the number of visits (in two studies) and admission and hospitalization (in one study) statistically significantly improved, economic outcomes in four other studies did not improve significantly.

-Table 4 shows the outcomes that were assessed only in intervention groups and has not been compared with control groups. These outcomes were categorized into the patientreported outcome category. mHealth apps had a positive impact on measured outcomes and there were no studies showing negative effects.

\section{Discussion}

In this systematic review, 10 studies (4 RCTs, 3 NRCTs, and 3 OWCs) were included regarding the effect of mHealth apps on patient self-management of asthma. These studies evaluated a wide range of outcomes related to asthma selfmanagement, which were classified into three main categories: clinical (e.g., asthma control), patient-reported (e.g., medication adherence and quality of life), and economic outcomes (e.g., healthcare visits). In general, most of the studies $(9 / 10,90 \%)$ were indicative of the positive impact of mHealth apps on most outcomes assessed. In contrast, only one of the studies ${ }^{29}$ did not report the positive impact on any of the outcomes assessed (including asthma control, asthma attacks, and adherence to treatment). Regarding the functionalities of the mHealth apps, nearly all interventions had the functionality of recording user-entered data and half of them had the functionality of providing educational information and reminders to patients.

Regarding the clinical outcomes (including control of asthma symptoms, lung function, and asthma attacks), 7 of the 10 studies assessed the impact of mHealth apps. Among the clinical outcomes, asthma control was investigated more than the others (lung function and asthma attacks), which indicates the importance of controlling this clinical outcome in patients with asthma. Five studies showed a positive, statistically significant improvement of this outcome, $28,30,31,49,50$ including two "strong" RCTs ${ }^{30,31}$ and one "strong" NRCTs. ${ }^{28}$ These findings were similar to the results of previous systematic reviews in some outcomes, but were different in others. The study by Marcano et al did not report conclusive evidence about the impact of smartphone apps on asthma self-management outcomes. ${ }^{23}$ But Hui and colleagues, by performing a meta-analysis of the three clinical trials, showed that 
Table 3 The categories of asthma outcomes and effects of mHealth apps on them in intervention groups compared with control

\begin{tabular}{|c|c|c|c|c|}
\hline \multirow[t]{2}{*}{ Outcome category } & \multirow[t]{2}{*}{ Outcomes } & \multicolumn{3}{|l|}{ Effect } \\
\hline & & $\begin{array}{l}\text { Positive effect } \\
\text { (statistically } \\
\text { significant) }\end{array}$ & $\begin{array}{l}\text { Positive effect } \\
\text { (not stated } \\
\text { about significance) }\end{array}$ & $\begin{array}{l}\text { Not statistically } \\
\text { significant }\end{array}$ \\
\hline \multirow{3}{*}{$\begin{array}{l}\text { Clinical } \\
\text { outcomes }\end{array}$} & Lung/Pulmonary function & 28,32 & - & 30 \\
\hline & Symptom/Asthma control & $28,30,31,49,50$ & - & 29 \\
\hline & Acute attack/Exacerbation of asthma & 50 & 30,32 & 29 \\
\hline \multirow{4}{*}{$\begin{array}{l}\text { Patient-reported } \\
\text { outcomes }\end{array}$} & Medications use/adherence & 28,32 & 31 & 29,30 \\
\hline & Self-efficacy & - & - & 29,50 \\
\hline & Quality of life & $30,32,49$ & - & 29 \\
\hline & Patient enablement & - & - & 29 \\
\hline \multirow[t]{4}{*}{ Economic outcomes } & Healthcare visits & 31,32 & - & $29,30,49$ \\
\hline & Days off work/study & - & - & 30 \\
\hline & Hospitalization/Admissions for asthma & 31 & - & $29,32,49$ \\
\hline & Healthcare costs & - & - & 29 \\
\hline
\end{tabular}

apps-based interventions have a positive impact on the outcome of asthma control. ${ }^{34}$ In contrast to the study by Marcano et al, which included only two studies (about the impact of mHealth apps on asthma self-management outcomes), in our study and the study by Hui et al, more studies were included that showed the positive impact of mHealth apps on improvement of this clinical outcome. In fact, this represents an

Table 4 Outcomes in intervention groups without control

\begin{tabular}{|l|l|}
\hline Outcomes & Study \\
\hline Patient satisfaction & $28,31,49,50$ \\
\hline Adherence to the intervention & 32,49 \\
\hline Mobile app usage & 31,50 \\
\hline $\begin{array}{l}\text { Adherence to self-management and risk } \\
\text { reduction recommendations }\end{array}$ & 49 \\
\hline Knowledge & 49 \\
\hline $\begin{array}{l}\text { Patients' perception of smartphone } \\
\text { app-supporting communication }\end{array}$ & 55 \\
\hline $\begin{array}{l}\text { Registered nurse/care coordinators' } \\
\text { perception of smartphone app-supporting } \\
\text { communication and accuracy of assessment } \\
\text { data }\end{array}$ & 55 \\
\hline $\begin{array}{l}\text { Adolescent asthma patients' preferences for } \\
\text { communicating with their caregivers and } \\
\text { medical provider }\end{array}$ & 57 \\
\hline $\begin{array}{l}\text { Caregivers' preferences for communication } \\
\text { with asthma patients }\end{array}$ & 57 \\
\hline $\begin{array}{l}\text { Self-management parameters } \\
\text { (self-observation/self-judgment/self-reaction) }\end{array}$ & 56 \\
\hline
\end{tabular}

increase in the number of studies in recent years and the importance of this issue.

In the case of patient-reported outcomes, while three studies showed a significant positive impact on quality of life, ${ }^{30,32,49}$ one study showed no impact. ${ }^{29}$ Similarly, Morrison and colleagues, by performing a meta-review, showed that digital interventions can improve the quality of life in patients with asthma. ${ }^{33}$ Hui et al also ${ }^{34}$ reported that in $50 \%$ of the interventions, quality of life improved over 6 to 30 months. The results of these three reviews show that IT-based interventions, especially smartphone apps, are appropriate interventions to improve the quality of life for asthma patients. Medication adherence is another patientreported outcome and the results of our study and those by Hui et $\mathrm{al}^{34}$ and Morrison et $\mathrm{al}^{33}$ similarly demonstrated that this outcome improved in some studies and did not improve in others. Although mHealth apps, by providing reminders, have the potential to improve medication adherence in patients with chronic diseases, ${ }^{51,52}$ their effects on asthma patients is mixed and consequently there is a need for further studies in this area.

mHealth apps can help lower costs by facilitating the delivery of care and connecting patients to their healthcare providers. ${ }^{53}$ In general, the results of this study showed that the number of visits, admissions, and hospitalization from economic outcomes improved in some studies and did not improve in others. Other economic outcomes, such as days off work or school and healthcare costs, did not improve in any study. Hui and colleagues in their systematic review showed that none of the smartphone apps had nonsignificant improvement in outcomes such as hospitalizations and emergency department visits. ${ }^{34}$ Also, it was reported by Marcano et al that information about the effectiveness and 
cost-effectiveness of smartphone and tablet self-management apps is conflicting. ${ }^{23}$ In some studies, the short duration of the study and the small sample size were reported as the causes of inefficiency of IT-based interventions on outcomes related to asthma self-management. ${ }^{23,33,54}$ Therefore, future studies on the effectiveness of mHealth app interventions on the economic outcomes of asthma should consider the items listed above.

The results of this study showed the functionalities of mHealth apps for patients with asthma and were divided into seven groups (inform, instruct, record, display, guide, remind/alert, and communicate). Eight of the 10 interventions had more than one functionality. Similarly, Hui et $\mathrm{al}^{34}$ classified the features of mobile-based interventions into seven categories (education, monitoring/electronic diary, action plans, medication reminders/prompts, facilitating professional support, raising patient awareness of asthma control, and decision support for professionals) and they concluded that the most successful interventions were those that had multiple functionalities. Due to numerous features provided by mHealth apps (such as recording patiententered data and providing educational information and reminders) for patients and their relatively good accessibility, it can be expected that they have more effectiveness than other IT-based interventions (such as short message, phone call, email, and Web site) which have either limited features or low accessibility. Therefore, it is suggested that the designers apply multiple functionalities/features in designing these types of apps.

\section{Strengths and Limitations}

There are strengths and limitations in this study. The strengths included the use of broad search strategy which led to the identification of a large number of studies (3,370 articles). Two authors independently extracted data and assessed the quality of studies. A valid and comprehensive tool was used to assess the quality of the included studies. However, this study also has four limitations. First, studies were identified based on searches in only three databases. It is possible that this failed to identify some eligible studies. To address this in part, reference list of included studies and relevant reviews were hand searched. The second limitation is related to differences in objectives, methods, outcomes, and quality of the included studies that caused more difficult comparisons. The third limitation is that non-English language articles and conference proceedings (due to lack of full-text) were excluded; so, we may have lost some valuable studies in this field. The last limitation is that, due to the emerging mHealth apps, the results of unpublished and inprogress studies related to this field were not available. As a result, our review does not show experiences drawn from non-English and unpublished studies. However, among electronically accessible English-language studies, we applied a comprehensive and robust search strategy.

\section{Implications for Practice}

According to the evidence found in this systematic review on the effectiveness of mHealth app-based interventions to improve self-management in patients with asthma, it is recommended to do the following to improve the acceptance of this type of interventions: use new models of self-care, including smartphone apps for better control of asthma, and enhance patients' quality of life, as well as use apps that provide multiple functionalities to patients.

\section{Implications for Future Research}

Given that the majority of the included studies (7/10, 70\%) were conducted on adults with asthma, few studies were done on special populations, including adolescents and pregnant women with asthma. No studies assessed the effectiveness of mHealth apps on children and healthcare providers, and only two studies were conducted on patients with uncontrolled asthma. ${ }^{28,29}$ So, it is suggested that future studies focus more on these populations. Since most of the included studies $(8 / 10$, $80 \%$ ) were conducted in developed countries, it is suggested that researchers conduct further investigations in developing and low-income countries. Considering that the results of this study showed that the effects of mHealth apps for patients with asthma on the outcomes related to adherence to medication/treatment and cost-effectiveness are not clear, further studies in this regard are needed.

\section{Conclusion}

Nearly all evaluated asthma apps have the functionality of recording patients' data and use more than one functionality. Multifunctional mHealth apps have good potential for improving control of asthma and quality of life in suffering patients. However, the effects of these interventions on outcomes related to healthcare costs and medication adherence are inconsistent.

\section{Multiple Choice Question}

In mHealth applications for patients with asthma, nearly all interventions have which of the following functionality?

A. Recording user-entered data

B. Providing educational information and reminders to patients

C. Displaying user-entered data

D. Providing instructions based on user-entered information

Correct Answer: The correct answer is A, Recording userentered data. The results of this systematic review showed that nearly all mobile health applications for patients with asthma had the functionality of recording user-entered data $(9 / 10,90 \%)$.

Protection of Human and Animal Subjects

Human and/or animal subjects were not included in the study.

Funding

This study was supported by a grant from Kashan University of Medical Sciences Research Council (number: 9606). 
Conflict of Interest

None.

\section{References}

1 Global Asthma Network. The Global Asthma Report 2014. Auckland, New Zealand 2014

2 Masoli M, Fabian D, Holt S, Beasley R; Global Initiative for Asthma (GINA) Program. The global burden of asthma: executive summary of the GINA Dissemination Committee report. Allergy 2004; 59(05):469-478

3 World Health Organization. Chronic obstructive pulmonary disease (COPD). Geneva, Switzerland: WHO. Available at: http:// www.who.int/respiratory/copd/en/. Accessed September 2017

4 Hall MJ, DeFrances CJ, Williams SN, Golosinskiy A, Schwartzman A. National hospital discharge survey: 2007 summary. 2010: US Department of Health and Human Services, Centers for Disease Control and Prevention, National Center for Health Statistics

5 Accordini S, Corsico AG, Braggion M, et al. The cost of persistent asthma in Europe: an international population-based study in adults. Int Arch Allergy Immunol 2013;160(01):93-101

6 Ehteshami-Afshar S, FitzGerald JM, Doyle-Waters MM, Sadatsafavi M. The global economic burden of asthma and chronic obstructive pulmonary disease. Int J Tuberc Lung Dis 2016;20(01):11-23

7 Nunes C, Pereira AM, Morais-Almeida M. Asthma costs and social impact. Asthma Res Pract 2017;3:1

8 Iltchev P, Śliwczyński A, Szynkiewicz P, Marczak M. Mobile Health Applications Assisting Patients with Chronic Diseases: Examples from Asthma Care, in M-Health Innovations for Patient-Centered Care. IGI Global; 2016:170-196

9 Andrews KL, Jones SC, Mullan J. Asthma self management in adults: a review of current literature. Collegian 2014;21(01):33-41

10 Smith JR, Mugford M, Holland R, et al. A systematic review to examine the impact of psycho-educational interventions on health outcomes and costs in adults and children with difficult asthma. Health Technol Assess 2005;9(23):iii-iv, 1-167

11 Welsh EJ, Hasan M, Li P. Home-based educational interventions for children with asthma. Cochrane Database Syst Rev 2011;(10): CD008469

12 British Thoracic Society Scottish Intercollegiate Guidelines Network. British guideline on the management of asthma: SIGN 153: Scottish Intercollegiate Guidelines Network; 2016. September 2016. Available at: https://www.brit-thoracic.org.uk/publication-library/bts-guidelines/

13 National Asthma Education and Prevention Program. Expert Panel Report 3 (EPR-3): Guidelines for the Diagnosis and Management of Asthma-Summary Report 2007. J Allergy Clin Immunol 2007;120(5, Suppl):S94-S138

14 GINA. Global Strategy for Asthma Management and Prevention (2017 Update). Global Initiative for Asthma; 2017

15 Razi SP, Piroozmand N, Zolfaghari M, Kazemnejad A, Firoozbakhsh S. Education of how-to-use peak flow meter and following up via SMS on asthma self-management. J Hayat 2013;18(04):19-27

16 López-Viña A, del Castillo-Arévalo E. Influence of peak expiratory flow monitoring on an asthma self-management education programme. Respir Med 2000;94(08):760-766

17 Morowatisharifabad M, Nadrian H, Falahi A, Mohammadi M. Predictors of self-management behaviors in patients with asthma based on Green's Model of Health Education Planning. J Sch Public Health Inst Public Health Res 2009;7(03):37-49

18 Ring N, Jepson R, Hoskins G, et al. Understanding what helps or hinders asthma action plan use: a systematic review and synthesis of the qualitative literature. Patient Educ Couns 2011;85(02):e131-e143

19 Roberts NJ, Younis I, Kidd L, Partridge MR. Barriers to the implementation of self management support in long term lung conditions. London J Prim Care (Abingdon) 2012;5(01):35-47

20 Kaya Z, Erkan F, Ozkan M, et al. Self-management plans for asthma control and predictors of patient compliance. J Asthma 2009; 46(03):270-275
21 Schnall R, Mosley JP, Iribarren SJ, Bakken S, Carballo-Diéguez A, Brown Iii W. Comparison of a user-centered design, self-management app to existing mHealth apps for persons living with HIV. JMIR Mhealth Uhealth 2015;3(03):e91

22 Jahns R, Houck P. Mobile Health Market Report 2013-2017. 2013

23 Marcano Belisario JS, Huckvale K, Greenfield G, Car J, Gunn LH. Smartphone and tablet self management apps for asthma. Cochrane Database Syst Rev 2013;11(11):CD010013

24 Beratarrechea A, Lee AG, Willner JM, Jahangir E, Ciapponi A, Rubinstein A. The impact of mobile health interventions on chronic disease outcomes in developing countries: a systematic review. Telemed J E Health 2014;20(01):75-82

25 Cafazzo JA, Casselman M, Hamming N, Katzman DK, Palmert MR. Design of an mHealth app for the self-management of adolescent type 1 diabetes: a pilot study. J Med Internet Res 2012;14(03):e70

26 El-Gayar O, Timsina P, Nawar N, Eid W. Mobile applications for diabetes self-management: status and potential. J Diabetes Sci Technol 2013;7(01):247-262

27 Hollenbach JP, Cushing A, Melvin E, McGowan B, Cloutier MM, Manice M. Understanding clinicians' attitudes toward a mobile health strategy to childhood asthma management: a qualitative study. J Asthma 2017;54(07):754-760

28 Cook KA, Modena BD, Simon RA. Improvement in asthma control using a minimally burdensome and proactive smartphone application. J Allergy Clin Immunol Pract 2016;4(04):730-737.e1

29 Ryan D, Price D, Musgrave SD, et al. Clinical and cost effectiveness of mobile phone supported self monitoring of asthma: multicentre randomised controlled trial. BMJ 2012;344:e1756

30 Zairina E, Abramson MJ, McDonald CF, et al. Telehealth to improve asthma control in pregnancy: a randomized controlled trial. Respirology 2016;21(05):867-874

31 Cingi C, Yorgancioglu A, Cingi CC, et al. The "physician on call patient engagement trial"(POPET): measuring the impact of a mobile patient engagement application on health outcomes and quality of life in allergic rhinitis and asthma patients. International Forum of Allergy and Rhinology-Wiley Online Library; 2015. Wiley Online Library

32 Liu WT, Huang CD, Wang CH, Lee KY, Lin SM, Kuo HP. A mobile telephone-based interactive self-care system improves asthma control. Eur Respir J 2011;37(02):310-317

33 Morrison D, Wyke S, Agur K, et al. Digital asthma self-management interventions: a systematic review. J Med Internet Res 2014; 16(02):e51

34 Hui CY, Walton R, McKinstry B, Jackson T, Parker R, Pinnock H. The use of mobile applications to support self-management for people with asthma: a systematic review of controlled studies to identify features associated with clinical effectiveness and adherence. J Am Med Inform Assoc 2017;24(03):619-632

35 Ansari R, Ahmadian L, Bazargan Harandi N, Mirzai M. Determining the content of a pediatric asthma website from parents' perspective: the Internet use and information needs. Int J Pediatr 2017;5 (06):5113-5123

36 Huang X, Matricardi PM. Allergy and asthma care in the mobile phone era. Clin Rev Allergy Immunol 2016. Doi: 10.1007/s12016016-8542-y

37 Shegog R, Bartholomew LK, Parcel GS, Sockrider MM, Mâsse L, Abramson SL. Impact of a computer-assisted education program on factors related to asthma self-management behavior. J Am Med Inform Assoc 2001;8(01):49-61

38 Kaushal R, Shojania KG, Bates DW. Effects of computerized physician order entry and clinical decision support systems on medication safety: a systematic review. Arch Intern Med 2003; 163(12):1409-1416

39 Garg AX, Adhikari NK, McDonald H, et al. Effects of computerized clinical decision support systems on practitioner performance and patient outcomes: a systematic review. JAMA 2005;293(10): $1223-1238$ 
40 Aitken M, Gauntlett C. Patient Apps for Improved Healthcare: From Novelty to Mainstream. Parsippany, NJ: IMS Institute for Healthcare Informatics; 2013

41 Chaet AV, Morshedi B, Wells KJ, Barnes LE, Valdez R. Spanishlanguage consumer health information technology interventions: a systematic review. J Med Internet Res 2016;18(08):e214

42 American Medical Association. Measures Development, Methodology, and Oversight Advisory Committee: Recommendations to PCPI Work Groups on Composite Measures. Chicago, IL: American Medical Association; 2010

43 Nabovati E, Vakili-Arki H, Taherzadeh Z, et al. Information technology-based interventions to improve drug-drug interaction outcomes: a systematic review on features and effects. J Med Syst 2017;41(01):12

44 Moher D, Liberati A, Tetzlaff J, Altman DG, PRISMA Group. Preferred reporting items for systematic reviews and meta-analyses: the PRISMA statement. PLoS Med 2009;6(07):e1000097

45 Thomas B, Ciliska D, Dobbins M, Micucci S. Quality Assessment Tool for Quantitative Studies Dictionary: The Effective Public Health Practice Project (EPHPP). McMaster University; 2008

46 National Collaborating Centre for Methods and Tools. Quality Assessment Tool for Quantitative Studies. Ontario: McMaster University Hamilton; 2008

47 Armijo-Olivo S, Stiles CR, Hagen NA, Biondo PD, Cummings GG. Assessment of study quality for systematic reviews: a comparison of the Cochrane Collaboration Risk of Bias Tool and the Effective Public Health Practice Project Quality Assessment Tool: methodological research. J Eval Clin Pract 2012;18(01):12-18

48 Effective Public Health Practice Project. Quality assessment tool for quantitative studies. 2010; Available at: http://www.ephpp. ca/tools.html
49 Licskai C, Sands TW, Ferrone M. Development and pilot testing of a mobile health solution for asthma self-management: asthma action plan smartphone application pilot study. Can Respir J 2013;20(04):301-306

50 Burbank AJ, Lewis SD, Hewes M, et al. Mobile-based asthma action plans for adolescents. J Asthma 2015;52(06):583-586

51 Dayer L, Heldenbrand S, Anderson P, Gubbins PO, Martin BC. Smartphone medication adherence apps: potential benefits to patients and providers. J Am Pharm Assoc (2003) 2013;53(02):172-181

52 Hayakawa M, Uchimura Y, Omae K, Waki K, Fujita H, Ohe K. A smartphone-based medication self-management system with realtime medication monitoring. Appl Clin Inform 2013;4(01): 37-52

53 West DM. Improving health care through mobile medical devices and sensors. Brookings Institution Policy Report 2013;10:1-13

54 Mosnaim GS, Powell LH, Rathkopf M. A review of published studies using interactive Internet tools or mobile devices to improve asthma knowledge or health outcomes. Pediatr Allergy Immunol Pulmonol 2012;25(02):55-63

55 Haze KA, Lynaugh J. Building patient relationships: a smartphone application supporting communication between teenagers with asthma and the RN care coordinator. Comput Inform Nurs 2013; 31(06):266-271, quiz 272-273

56 Carpenter DM, Geryk LL, Sage A, Arrindell C, Sleath BL. Exploring the theoretical pathways through which asthma app features can promote adolescent self-management. Transl Behav Med 2016;6 (04):509-518

57 Roberts CA, Geryk LL, Sage AJ, Sleath BL, Tate DF, Carpenter DM. Adolescent, caregiver, and friend preferences for integrating social support and communication features into an asthma selfmanagement app. J Asthma 2016;53(09):948-954 


\section{Appendix Database search strategy}

\section{PubMed}

(Asthma* OR wheez* OR "asthma"[MeSH Terms]) AND (telephone[Title/Abstract] OR mobile[Title/Abstract] OR phone [Title/Abstract] OR smartphone[Title/Abstract] OR smartphone[Title/Abstract] OR mhealth[Title/Abstract] OR mhealth[Title/Abstract] OR "m health"[Title/Abstract] OR ehealth[Title/Abstract] OR ehealth[Title/Abstract] OR "e health"[Title/Abstract] OR telecare[Title/Abstract] OR telecare[Title/Abstract] OR telemedicine[Title/Abstract] OR telemed[Title/Abstract] OR telehealth[Title/Abstract] OR telehealth[Title/Abstract] OR telenursing[Title/Abstract] OR tele-nursing[Title/Abstract] OR android[Title/Abstract] OR samsung[Title/Abstract] OR sony[Title/Abstract] OR ios [Title/Abstract] OR iphone*[Title/Abstract] OR ipad*[Title/ Abstract] OR ipod*[Title/Abstract] OR "tablet device"[Title/ Abstract] OR app[Title/Abstract] OR apps[Title/Abstract] OR handheld[Title/Abstract] OR hand-held[Title/Abstract] OR "personal digital"[Title/Abstract] OR PDA[Title/Abstract] OR blackberry[Title/Abstract] OR nokia[Title/Abstract] OR symbian[Title/Abstract] OR HTC[Title/Abstract] OR Palm[Title/ Abstract] OR INQ[Title/Abstract] OR "tablet computer"[Title/ Abstract] OR telemedicine[MeSH Terms] OR telephone [MeSH Terms] OR Computers, Handheld[MeSH Terms] OR Mobile Applications[MeSH Terms])

\section{Scopus}

TITLE-ABS KEY ((asthma* OR wheez ${ }^{*}$ ) AND (telephone OR mobile OR phone OR smartphone OR smart-phone OR mhealth OR m-health OR "m health" OR e-health OR ehealth OR "e health" OR telecare OR tele care OR telemedicine OR telemed OR telehealth OR tele-health OR telenursing OR telenursing OR android OR samsung OR sony OR ios OR iphone* OR ipad* OR ipod* OR "tablet device" OR app OR apps OR handheld OR hand-held OR "personal digital" OR pda OR blackberry OR nokia OR symbian OR htc OR palm OR inq OR "tablet computer")) AND (LIMIT-TO (LANGUAGE, "English")) AND (LIMIT-TO (SRCTYPE, "j")) AND (LIMIT-TO (PUBYEAR, 2016) OR LIMIT-TO (PUBYEAR, 2015) OR LIMIT-TO (PUBYEAR, 2014) OR LIMIT-TO (PUBYEAR, 2013) OR LIMIT-TO (PUBYEAR, 2012) OR LIMIT-TO (PUBYEAR, 2011) OR LIMITTO (PUBYEAR, 2010) OR LIMIT-TO (PUBYEAR, 2009) OR LIMIT-TO (PUBYEAR, 2008) OR LIMIT-TO (PUBYEAR, 2007) OR LIMIT-TO (PUBYEAR, 2006) OR LIMIT-TO (PUBYEAR, 2005) OR LIMIT-TO (PUBYEAR, 2004) OR LIMIT-TO (PUBYEAR, 2003) OR LIMIT-TO (PUBYEAR, 2002) OR LIMIT-TO (PUBYEAR, 2001) OR LIMIT-TO (PUBYEAR, 2000)) AND (LIMIT-TO (DOCTYPE, "ar") OR LIMIT-TO (DOCTYPE, "ip"))

\section{Cochrane}

(Asthma* OR wheez*)AND (telephone OR mobile OR phone OR smartphone OR smart-phone OR mhealth OR m-health OR "m health" OR e-health OR ehealth OR "e health" OR telecare OR tele-care OR telemedicine OR telemed OR telehealth OR telehealth OR telenursing OR tele-nursing OR android OR samsung OR sony OR ios OR iphone* OR ipad* OR ipod* OR "tablet device" OR app OR apps OR handheld OR hand-held OR "personal digital" OR PDA OR blackberry OR nokia OR symbian OR HTC OR Palm OR INQ OR "tablet computer"

Table A1 Technology functionality framework ${ }^{40}$

\begin{tabular}{|c|c|}
\hline $\begin{array}{l}\text { Functionality } \\
\text { subcategory }\end{array}$ & Definition \\
\hline Inform & $\begin{array}{l}\text { Provide information in a variety of formats } \\
\text { (text, photo, video) }\end{array}$ \\
\hline Instruct & Provide instructions to the user \\
\hline Record & Capture user-entered data \\
\hline Display & $\begin{array}{l}\text { Graphically display user-entered data/ } \\
\text { output user-entered data }\end{array}$ \\
\hline Guide & $\begin{array}{l}\text { Provide guidance based on user-entered } \\
\text { information (e.g., recommend a physician } \\
\text { consultation or course of treatment) }\end{array}$ \\
\hline Remind/Alert & Provide reminders to the user \\
\hline Communicate & $\begin{array}{l}\text { Provide communication with health care } \\
\text { provider/patients and/or provide links to } \\
\text { social networks }\end{array}$ \\
\hline
\end{tabular}

Table A2 Categories of outcome measures ${ }^{42}$

\begin{tabular}{|l|l|}
\hline $\begin{array}{l}\text { Types of outcome } \\
\text { measures }\end{array}$ & Examples \\
\hline Clinical outcomes & Infant death rates \\
\hline Mortality & $\begin{array}{l}\text { Reduced rates of } \\
\text { preeclampsia; reduced rates } \\
\text { of gestational diabetes }\end{array}$ \\
\hline Morbidity & $\begin{array}{l}\text { Blood pressure levels, blood } \\
\text { glucose levels }\end{array}$ \\
\hline outcomes & $\begin{array}{l}\text { Reduction in chest pain; } \\
\text { reduced depression } \\
\text { episodes }\end{array}$ \\
\hline Clinical events & $\begin{array}{l}\text { Stroke; Cancer; adverse } \\
\text { events during childbirth }\end{array}$ \\
\hline Patient-reported outcomes & \multicolumn{2}{|l|}{} \\
\hline Health status & $\begin{array}{l}\text { Quality of life-health status } \\
\text { as perceived by the } \\
\text { individual } \\
\text { - Functional measures- } \\
\text { SF-36, PROMIS } \\
\text { Pre- and posttreatment } \\
\text { physical function } \\
\text { Pre- and posttreatment } \\
\text { mental health (e.g., } \\
\text { depression severity) } \\
\text { Pre- and posttreatment } \\
\text { social/role function } \\
\text { Other measures of health } \\
\text { status such as pain, } \\
\text { vitality, perceived well- } \\
\text { being, health risk status, } \\
\text { etc. }\end{array}$ \\
\hline
\end{tabular}


Table A2 (Continued)

\begin{tabular}{|c|c|}
\hline $\begin{array}{l}\text { Types of outcome } \\
\text { measures }\end{array}$ & Examples \\
\hline \multicolumn{2}{|l|}{ Clinical outcomes } \\
\hline $\begin{array}{l}\text { Patient experiences with } \\
\text { care (patient satisfaction, } \\
\text { patient engagement/patient } \\
\text { preference, patient } \\
\text { education) }\end{array}$ & $\begin{array}{l}\text { Consumer assessment } \\
\text { (CAHPS); quality of life, } \\
\text { compliance with treatment } \\
\text { regimen; provider retention; } \\
\text { shared decision making; } \\
\text { engagement of family and } \\
\text { friends; patient knowledge } \\
\text { and understanding }\end{array}$ \\
\hline \multicolumn{2}{|l|}{ Economic outcomes } \\
\hline Resource use/costs & $\begin{array}{l}\text { Healthcare service } \\
\text { utilization; cost per episode } \\
\text { of care }\end{array}$ \\
\hline
\end{tabular}

Table A3 Evaluation of intervention features

\begin{tabular}{|c|c|c|c|c|c|c|c|c|c|c|}
\hline \multirow[t]{2}{*}{ Functionality } & \multicolumn{10}{|c|}{ Study } \\
\hline & 32 & 29 & 55 & 49 & 50 & 31 & 56 & 28 & 57 & 30 \\
\hline Inform & - & - & $v$ & $\nu$ & $\nu$ & $\nu$ & - & $\nu$ & - & - \\
\hline Instruct & - & - & - & - & $\nu$ & - & - & $r$ & - & $r$ \\
\hline Record & $\boldsymbol{\nu}$ & $\boldsymbol{v}$ & $v$ & レ & $\nu$ & $\boldsymbol{\nu}$ & $\checkmark$ & レ & - & $r$ \\
\hline Display & - & $v$ & $v$ & $\nu$ & - & - & 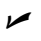 & & - & - \\
\hline Guide & - & - & $v$ & $\nu$ & - & - & - & - & - & $\nu$ \\
\hline Remind/Alert & - & - & - & $\boldsymbol{V}$ & レ & $r$ & $\nu$ & $\boldsymbol{v}$ & - & - \\
\hline Communicate & - & & $v$ & - & - & $r$ & $\boldsymbol{v}$ & - & $\nu$ & - \\
\hline
\end{tabular}

